(2) Open Access Full Text Article

\title{
Comparison study of OCT, HRT andVF findings among normal controls and patients with pseudoexfoliation, with or without increased IOP
}

This article was published in the following Dove Press journal:

Clinical Ophthalmology

I December 2014

Number of times this article has been viewed

Fryni Riga

Ilias Georgalas

Panagiotis Tsikripis

Dimitrios Papaconstantinou

Department of Ophthalmology, University of Athens, Athens, Greece
Purpose: To compare and evaluate optic nerve head $(\mathrm{ONH})$ and retinal nerve fiber layer (RNFL) measurements obtained with the optical coherence tomography (OCT) and the Heidelberg retina tomography (HRT) to visual field (VF) parameters in normal and in patients with pseudoexfoliation with or without increased intraocular pressure (IOP).

Methods: A total of 96 subjects were included in our study aged between 65 years and 78 years. The normal group consisted of 28 subjects (14 men and 14 women). Out of the total number of patients, 68 patients who showed pseudoexfoliation (21 men and 47 women) were divided into two groups. Of these, the first group had pseudoexfoliation with increased IOP and the second group showed deposits of pseudoexfoliative material without an increase in IOP. The normal controls were randomly chosen and restricted to those without any glaucomatous optic disc damages, VF defects, and an IOP $<15 \mathrm{mmHg}$. All subjects were prospectively included for repeated measurements of IOP, OCT, HRT, and VFs during the same visit by the same examiner and all measurements were repeated every 3 months.

Results: Mean RNFL thickness measured by OCT was larger in the normal controls than in the other two groups (98.04 $\mu \mathrm{m}$ (first group) vs $75.42 \mu \mathrm{m}$ and $97.02 \mu \mathrm{m}$ (second group), $P<0.05$ ). Four-quadrant RNFL thickness measurements were significantly different between the normal and the group $1(P<0.05)$ but not with the group $2(P>0.05)$. Rim area had a mean difference of -0.44 , whereas cup-to-disc ratio $(\mathrm{C} / \mathrm{D})$ showed a mean difference of 0.31 , thus being significantly different between the normal and the two groups (all $P<0.05$ ). The median of the mean deviation parameter of VFs was -0.28 for the normal vs -0.32 and -0.18 for the other two groups, whereas pattern standard deviation median difference was 0.89 for the normal and 1.32 and 1.20 for the other two groups, respectively $(P<0.05)$.

Conclusion: Both OCT and HRT showed early ONH and RNFL changes in their parameters and did not correlate with the normal findings of the automated perimetry.

Keywords: pseudoexfoliation syndrome, pseudoexfoliation glaucoma, optical coherence tomography (OCT), Heidelberg retina tomograph (HRT), retinal nerve fiber layer (RNFL), visual fields (VFs)

\section{Introduction}

Pseudoexfoliation syndrome is an age-related systemic disease, characterized by the production and accumulation of small, white deposits of a fibrillar extracellular material in many ocular and extraocular tissues. ${ }^{1-3}$ The events from the eye include all structures of anterior segment, as well as the conjunctiva and orbital structures. In 2003, Ritch et al explained the relation between glaucoma and pseudoexfoliation. ${ }^{1,2,4}$ In the early $1980 \mathrm{~s}$ though, Roth and Epstein reported that glaucoma was present in patients with pseudoexfoliation syndrome. ${ }^{3}$ The prevalence of pseudoexfoliation syndrome in glaucomatous
Correspondence: Panagiotis Tsikripis Department of Ophthalmology, University of Athens, Leoforos Mesogion 154, Athens 115 27, Greece Email ptsikripis@gmail.com 
populations is much higher than in age-matched nonglaucomatous ones as noted by Puska et al and Konstas et al. ${ }^{5-7}$ In the last few years, many imaging systems have been proposed and supported for the quantitative assessment of morphological changes in glaucoma, which relate to the optic nerve head $(\mathrm{ONH})$ and the optic fiber layer, with optical coherence tomography (OCT) and Heidelberg retina tomograph (HRT) the most known. The OCT is an optical analog of b-ultrasound based on light emission wavelength near the infrared spectrum $(840 \mathrm{~nm})$ and generates optical tissue sections with resolution

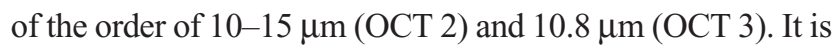
able to measure the thickness of the peripapillary nerve fiber layer, a method that has been proven by studies to have good sensitivity and specificity in the discrimination of glaucoma and non-glaucoma patients. ${ }^{8-12}$ The Heidelberg retina tomograph (HRT) is a laser scanning system that is designed for receiving and analyzing three-dimensional images of the posterior segment of the eye as described by Weinreb et al. ${ }^{12}$ The HRT II takes a series of up to 64 optical sections at depth intervals of $1 / 16$ of a millimeter. The number of pictures taken varies with the thickness of the tissue being examined. The image field is $15^{\circ} \times 15^{\circ}$, with a density of 384 pixels $\times 384$ pixels. The tomography is derived from the estimate of the maximum intensity in each pixel of the image resulting in a table of surface height measurements with dimensions of 384 pixels $\times 384$ pixels, and is presented as a color-coded map, with the deepest colors representing more superficial structures and lighter representing deeper structures. ${ }^{13}$ Finally, measurements with HRT are shown by studies to be reproducible and correlated with the histological findings. ${ }^{14-16}$ In this study, we have tried to compare the thickness of the retinal nerve fiber layer (RNFL) around ONH obtained by OCT and HRT to visual field (VF) parameters in normal controls and in patients with pseudoexfoliation with increased intraocular pressure (IOP), and pseudoexfoliation without an increase in IOP.

\section{Materials and methods}

This prospective study was performed in the Department of Ophthalmology of Athens University, at G Gennimatas Hospital. The study was approved by the institutional review board of the hospital, and all study procedures adhered to the tenets of the Declaration of Helsinki. After a detailed explanation of the procedure benefits and risks, informed consent was obtained from all patients. None of the patients refused to enroll, during the course of the study.

During a 7-month period, a total of 112 subjects were randomly selected to be included in our study. IOP was also repeatedly measured three times per day so as to select the patients with elevated IOP. Finally, only 96 patients (of age between 65 years and 78 years) fulfilled our criteria and were able to participate during the 3 -year period. The normal group consisted of 28 subjects (14 men and 14 women). Out of the total number of patients, 68 patients who showed pseudoexfoliation ( 21 men and 47 women) were divided into two groups. Of these, the first group had pseudoexfoliation with increased IOP and the second group showed deposits of pseudoexfoliative material without an increase in IOP. The normal controls were randomly chosen and restricted to those without any glaucomatous optic disc damages, VF defects, and an IOP $<16 \mathrm{mmHg}$.

The right eyes of all subjects were chosen to participate in our study. The restriction of the study to the right eye of each patient for each group was to facilitate statistical analysis.

IOP was by protocol first measured with Goldmann applanation tonometer followed by OCT measurement (Stratus OCTIII), HRT (using the Heidelberg HRT3), and VFs obtained by Humphrey automated perimetry (Allergan-Humphrey) central 30-2 program. RNFL thickness was measured with OCT for each of the four quadrants surrounding the disc and a mean value was calculated. The parameters used were average (AVG), superior (S), inferior (I), temporal (T), and nasal (N). In HRT, the ONH border was drawn inside the inner boundary of the scleral ring of Elschnig and cup-to-disc ratio (C/D) and rim area were the two variables used. VF indices for statistical analysis included mean deviation (MD) and pattern standard deviation (PSD). All the measurements of IOP, OCT, HRT, and VFs were made on the same day by same observer.

The aim was to compare the thickness of the RNFL around ONH obtained by OCT and HRT to VF parameters in normal and in patients with pseudoexfoliation of different IOP.

Exclusion criteria were high myopia, cataract, diabetic retinopathy, optic nerve diseases, and corneal opacities.

\section{Statistical analysis}

The statistical analysis was performed with the software SPSS 19.0. Since the investigation of changes concerned more than one distinct group, the methods selected were that

Table I The three groups divided by sex

\begin{tabular}{lllll}
\hline Group & & \multicolumn{2}{l}{ Sex } & Total \\
\cline { 3 - 4 } & & Men & Women & \\
\hline Normal & Count & 14 & 14 & 28 \\
I & Count & 11 & 17 & 28 \\
2 & Count & 10 & 30 & 40 \\
Total & Count & 35 & 61 & 96 \\
\hline
\end{tabular}


Table 2 Descriptive measures by group and differences in means and medians between normal, group I, and group 2

\begin{tabular}{|c|c|c|c|c|c|c|}
\hline \multirow[t]{2}{*}{ Variables } & \multicolumn{2}{|c|}{ Normal } & \multicolumn{2}{|c|}{ Group I } & \multicolumn{2}{|c|}{ Group 2} \\
\hline & Mean & SD & Mean & SD & Mean & SD \\
\hline IOP (mmHg) & 14.32 & 1.634 & 20.30 & 3.024 & 16.85 & 1.875 \\
\hline OCT AVG thickness $(\mu \mathrm{m})$ & 98.04 & 6.987 & 75.42 & 10.764 & 97.02 & 7.132 \\
\hline OCT S thickness $(\mu \mathrm{m})$ & 120.78 & 12.728 & 89.54 & 21.114 & 119.78 & 12.442 \\
\hline OCT T thickness $(\mu \mathrm{m})$ & 75.31 & 11.356 & 57.61 & $12.7 \mid 4$ & 73.25 & II.047 \\
\hline OCT I thickness $(\mu \mathrm{m})$ & 125.17 & 10.864 & 97.89 & 22.376 & 124.20 & 10.593 \\
\hline OCT $N$ thickness $(\mu \mathrm{m})$ & 75.80 & 9.952 & 56.43 & 13.544 & 74.60 & 9.660 \\
\hline HRT C/D ratio & 0.32 & 0.111 & 0.64 & 0.168 & 0.33 & 0.113 \\
\hline HRT rim area $\left(\mathrm{mm}^{2}\right)$ & 1.60 & 0.330 & 1.06 & 0.296 & 1.50 & 0.230 \\
\hline VF MD (dB) & -0.28 & 1.082 & -0.32 & 1.143 & -0.18 & 1.072 \\
\hline VF PSD & 0.89 & 0.351 & 1.32 & 0.318 & 1.20 & 0.302 \\
\hline
\end{tabular}

Abbreviations: SD, standard deviation; IOP, intraocular pressure; OCT, optical coherence tomography; AVG, average; S, superior; T, temporal; I, inferior; N, nasal; HRT, Heidelberg retina tomography; C, cup; D, disc; VF, visual field; MD, mean deviation; PSD, pattern standard deviation.

of the single-factor analysis of variance and the application of nonparametric tests, ie, the Kruskal-Wallis test. Statistical analyses were conducted by applying suitably the two methods, depending on the occasion. Goldmann applanation tonometer was used for the measurements of the statistics presented as well as OCT, HRT, and Humphrey VF.

Normality of variables was tested using graphical (histograms) and mathematical methods, in particular the Kolmogorov-Smirnov and Shapiro-Wilk statistics. The Shapiro-Wilk test was a little more flexible on the number of comments, but both gave similar results.

Finally, the homoscedasticity variables (homogeneity of variances) were controlled with the Levene test.

\section{Results}

As shown in Table 1, sex of the patients in three groups showed no statistical difference. In Table 2, we can see the comparisons of OCT parameters (AVG, S, T, I, N) along with HRT variables $(\mathrm{C} / \mathrm{D}$, rim area) and VFs for the right eye in the three study groups.
From the comparison of the levels of the four peripapillary quadrants among the three groups, we can see that the mean values of AVG, S, T, I, N, and rim area in the first group are lower than those of the second group as well as of the normal.

Mean values of IOP and $\mathrm{C} / \mathrm{D}$, on the other hand, are higher in the first group than those of the second and the normal one. As we found, MD and PSD values were significantly high for all groups. According to the results in Table 3, in all cases, the observed differences between group 1, group 2, and the normal are statistically significant at the level of 5\%. This is also schematically illustrated in Figures 1-10.

We also observed during the study that in the first group, OCT measurements for average RNFL thickness and for each of the peripapillary quadrants significantly correlated with HRT measurements. Among the OCT measurements, the superior RNFL thickness measurement showed the most association with calculated HRT parameters.

Concerning the second group, the OCT variables (AVG, $\mathrm{S}, \mathrm{I}, \mathrm{T}, \mathrm{N})$ showed to be significantly correlated with our

Table 3 Mean differences between the three groups

\begin{tabular}{llll}
\hline Variables & Means & & Group 2-normal \\
\cline { 2 - 4 } & Group I-normal & Group I-group 2 & 5.98 \\
\hline IOP right $(\mathrm{mmHg})$ & 3.45 & 2.53 & 1.01 \\
OCT AVG thickness right $(\mu \mathrm{m})$ & -22.62 & -21.6 & -1 \\
OCT S thickness right $(\mu \mathrm{m})$ & -30.24 & -99.67 & -2.06 \\
OCT T thickness right $(\mu \mathrm{m})$ & -15.64 & -17.7 & -0.97 \\
OCT I thickness right $(\mu \mathrm{m})$ & -26.31 & -27.28 & -1.2 \\
OCT N thickness right $(\mu \mathrm{m})$ & -18.17 & -19.37 & 0.01 \\
HRT C/D right ratio & 0.31 & 0.32 & -0.1 \\
HRT rim area right $\left(\mathrm{mm}^{2}\right)$ & -0.44 & -0.54 & -0.86 \\
VF MD right $(\mathrm{dB})$ & -0.96 & -0.46 & 0.43 \\
VF PSD right & 0.12 & 0.31 & \\
\hline
\end{tabular}

Abbreviations: IOP, intraocular pressure; OCT, optical coherence tomography; AVG, average; S, superior; T, temporal; I, inferior; N, nasal; HRT, Heidelberg retina tomography; $C$, cup; $D$, disc; VF, visual field; MD, mean deviation; PSD, pattern standard deviation. 


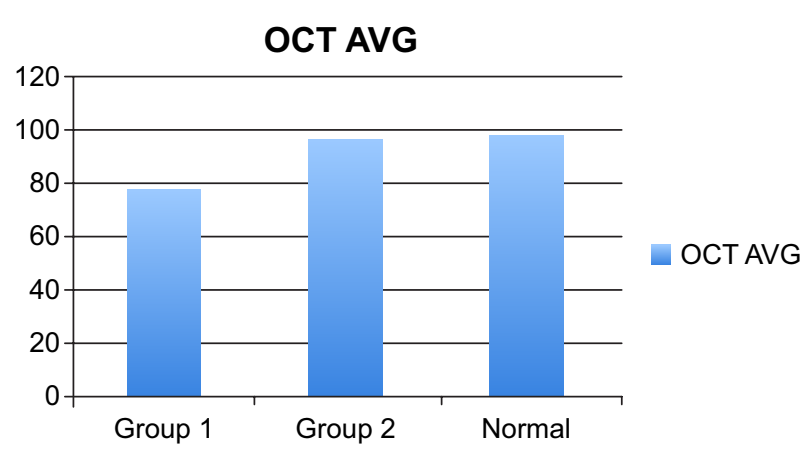

Figure I Mean values of OCT (AVG thickness, $\mu \mathrm{m}$ ) by group. Abbreviations: OCT, optical coherence tomography; AVG, average.

HRT parameters $\mathrm{C} / \mathrm{D}$ ratio and rim area. There were no statistically significant differences between the second and the normal group in the OCT and HRT measurements.

In Figures 1-5, we observe higher values of the parameters of OCT (AVG, S, I, T, N) in all controls for group 2 and the normal compared with group 1, throughout the duration of our study.

In Figures 6 and 7, we examined the correlation parameters of HRT (C/D ratio, rim area) in the three groups and we observed that the $\mathrm{C} / \mathrm{D}$ ratio in the first group is increased and the rim area is shown reduced.

In Figures 8 and 9, we examined the variable values of MD and PSD in all three groups.

The VF parameters MD and PSD in the two pseudoexfoliation groups showed a significant correlation with the normal one.

\section{Discussion}

In our study, we found that the eyes of the first group that had pseudoexfoliation with increased IOP and did not show progression by using the VFs had significantly higher rates

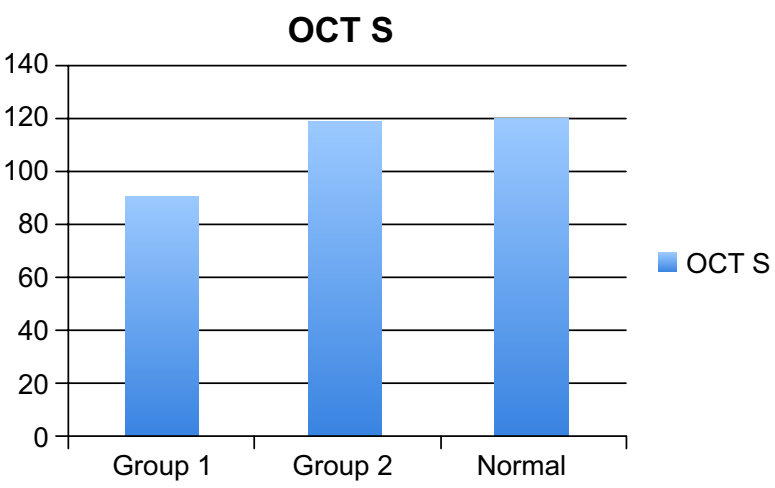

Figure 2 Mean values of OCT (S thickness, $\mu \mathrm{m}$ ) by group. Abbreviations: OCT, optical coherence tomography; S, superior.

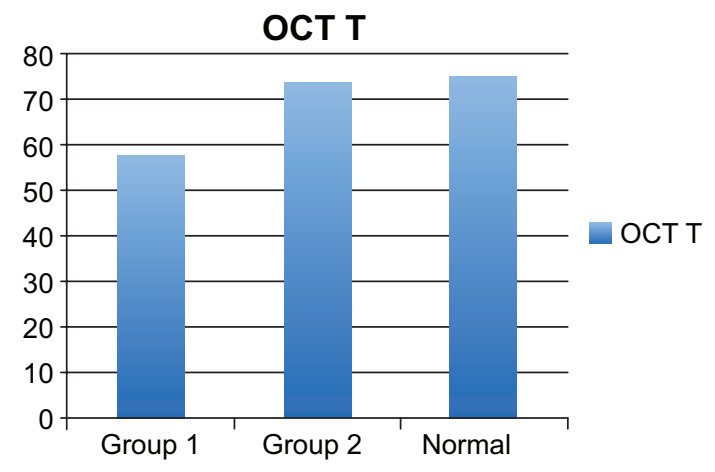

Figure 3 Mean values of OCT ( $T$ thickness, $\mu \mathrm{m}$ ) by group. Abbreviations: OCT, optical coherence tomography; $\mathrm{T}$, temporal.

of RNFL loss over time as measured by OCT and HRT compared with the normal and the second group (eyes with pseudoexfoliative material without an increase in IOP). The lower significant difference between the normal and the second group was most probably found due to the lower IOP measurements. Nevertheless, the second group also showed a small amount of RNFL and ONH damage during our study as shown in OCT and HRT compared to normal.

According to the results in both pseudoexfoliation groups in the 3-year period, quantitative comparisons showed a significantly larger rim area for our second group than the first group (median difference of -0.44 ). C/D ratio showed statistically different values for each of the two groups with the second having by far the lower values (median difference of 0.31), both compared to normal.

We also observed higher values of the parameters of OCT (AVG, S, I, T, N) in all controls for group 2 compared with group 1 and the normal, throughout the duration of our study (Figures 1-5).

Rim area in all groups also showed high association with the superior, inferior, temporal, and nasal quadrants of RNFL

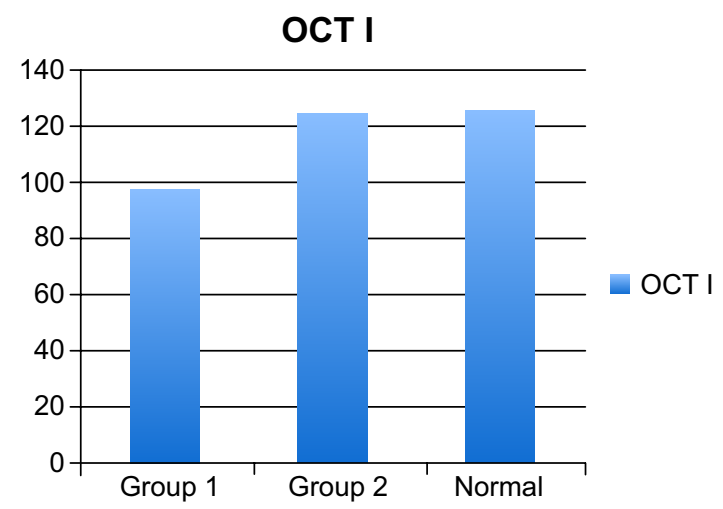

Figure 4 Mean values of OCT (I thickness, $\mu \mathrm{m}$ ) by group. Abbreviations: OCT, optical coherence tomography; I, inferior. 


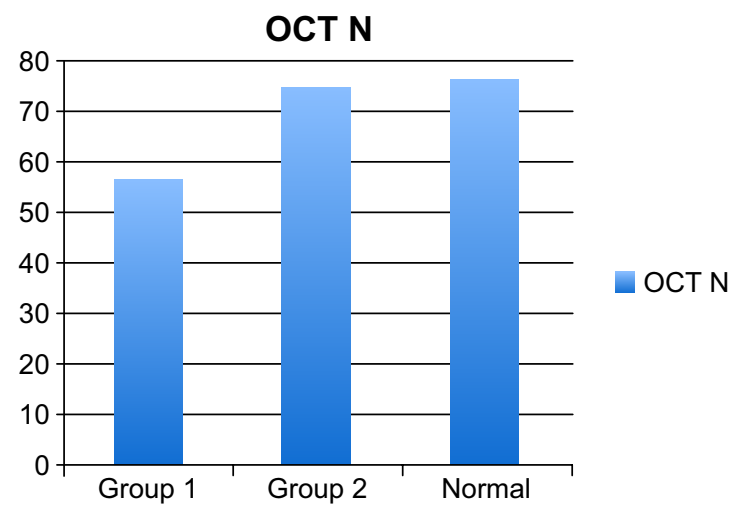

Figure $\mathbf{5}$ Mean values of OCT ( $N$ thickness, $\mu \mathrm{m}$ ) by group. Abbreviations: $\mathrm{OCT}$, optical coherence tomography; $\mathrm{N}$, nasal.

thickness. It is known from studies like that of Lan et al that regarding the correlation between the anatomical variables of HRT and VF indices, many of the parameters of HRT have a statistically significant correlation with the indices of the VF, with the largest correlation recorded between the VF indices and parameters, rim area and cup shape measure of HRT. ${ }^{17-21}$

We can say by observation of the results that the changes in the four quadrants of RNFL thickness in all groups correlate with the $\mathrm{ONH}$ changes as shown in $\mathrm{C} / \mathrm{D}$ ratio and rim area.

It should be noted that changes might occur in different quadrants of the ONH (ie, T, N, I, S) and RNFL as glaucoma progresses, which could explain why a single variable may not be able to detect all progressing glaucoma lesions. ${ }^{19}$

It is described that glaucoma lesions occur more commonly in eyes with exfoliation syndrome than in those without it. In fact, exfoliation syndrome was recognized as the most common identifiable cause of glaucoma. ${ }^{22}$ Patients with exfoliation syndrome are also predisposed to develop angleclosure glaucoma, and glaucoma in exfoliation syndrome

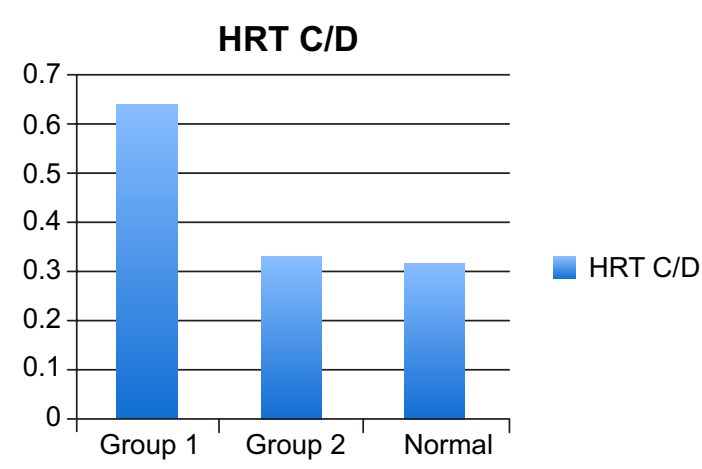

Figure 6 Mean values of HRT (C/D ratio) by group.

Abbreviations: HRT, Heidelberg retina tomography; $C$, cup; $D$, disc.

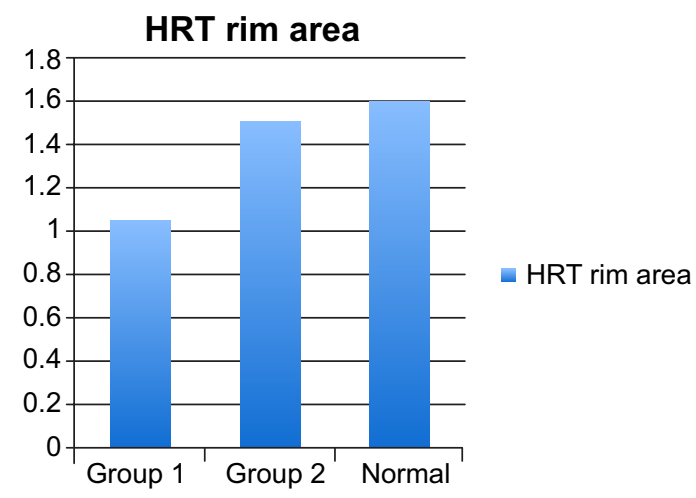

Figure 7 Mean values of HRT (rim area, $\mathrm{mm}^{2}$ ) by group. Abbreviation: HRT, Heidelberg retina tomography.

has a more serious clinical course and worse prognosis than primary open-angle glaucoma.

It has been suggested by Ritch et al that exfoliation material itself predisposes for glaucomatous lesions even in the absence of elevated IOP. ${ }^{22}$ At any specific IOP level, eyes with exfoliation syndrome and pseudoexfoliative material are more likely and predisposed to have glaucomatous damage than are eyes without exfoliation as is also shown in our study in comparison with the normal control group.

OCT and HRT are two imaging systems for the quantitative assessment of morphological changes in glaucoma, that is, of the ONH and the RNFL assisting the well-tested method of VFs. ${ }^{23-26}$

The aim of our study was to compare and evaluate $\mathrm{ONH}$ and RNFL measurements obtained with the OCT and the HRT to VF parameters in normal and in patients with pseudoexfoliation with or without increased IOP.

Changes were observed in the parameters of OCT and HRT in both groups 1 and 2, and as expected, not in the normal. In both groups, these changes did not

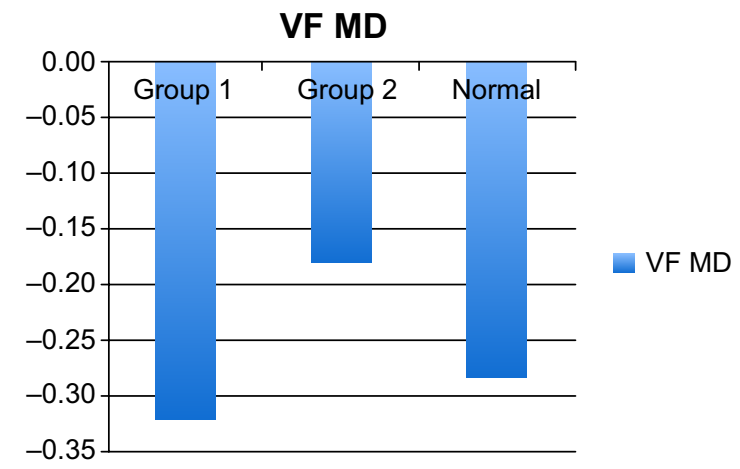

Figure 8 Mean values of VF MD (dB) by group.

Abbreviations: VF, visual field; MD, mean deviation. 


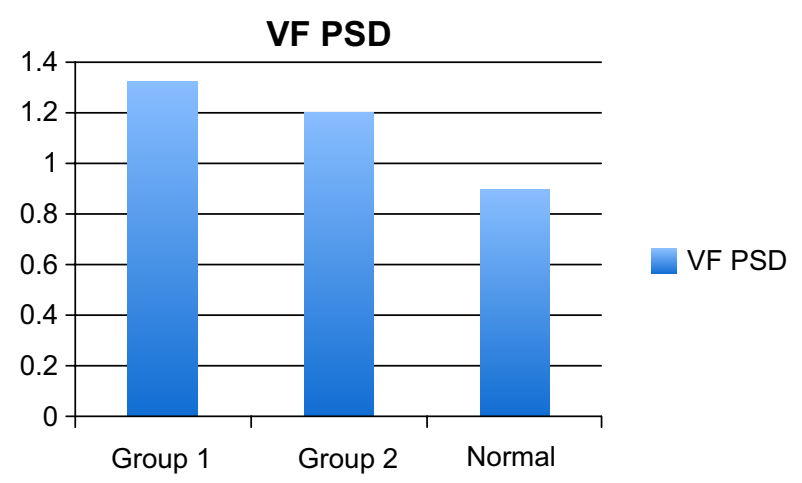

Figure 9 Mean values of VF PSD by group.

Abbreviations: VF, visual field; PSD, pattern standard deviation.

correlate with the VFs, which appeared normal in all three groups.

The results suggest that ONH and RNFL damage pattern in patients with pseudoexfoliation with or without increased IOP is different from normal and does not correlate with the findings in the VF.

Thus, both OCT and HRT were able to discriminate eyes with progressing disease from eyes that remained stable according to VFs. Both are important and should be used along with automated perimetry to accurately evaluate a patient with pseudoexfoliation and increased or no IOP, assisting the clinician in the early diagnosis, early detection of progression of glaucoma, and a correct follow-up for a better treatment outcome.

Further research would be useful with larger numbers of patients, and longer follow-ups are required to confirm these findings and improve patient care.

\section{Disclosure}

The authors report no conflicts of interest in this work.

\section{References}

1. Ritch R, Schlötzer-Schrehardt U, Konstas AG. Why is glaucoma associated with exfoliation syndrome? Prog Retin Eye Res. 2003;22(3): 253-275. [Review].

2. Koliakos GG, Konstas AG, Schlötzer-Schrehardt U, et al. 8-Isoprostaglandin $\mathrm{F} 2 \mathrm{a}$ and ascorbic acid concentration in the aqueous humour of patients with exfoliation syndrome. Br J Ophthalmol. 2003; 87(3):353-356.

3. Roth M, Epstein DL. Exfoliation syndrome. Am J Ophthalmol. 1980; 89(4):477-481.

4. Ritch R, Schlötzer-Schrehardt U. Exfoliation (pseudoexfoliation) syndrome: toward a new understanding. Proceedings of the First International Think Tank. Acta Ophthalmol Scand. 2001;79(2):213-217.

5. Puska P, Vesti E, Tomita G, Ishida K, Raitta C. Optic disc changes in normotensive persons with unilateral exfoliation syndrome: a 3-year follow-up study. Graefes Arch Clin Exp Ophthalmol. 1999;237(6):457-462.

6. Konstas AG, Dimitracoulias N, Konstas PA. Exfoliationssyndrom und Offenwinkelglaukom [Exfoliation syndrome and open angle glaucoma]. Klin Monbl Augenheilkd. 1993;202(4):259-268. [Review, German].

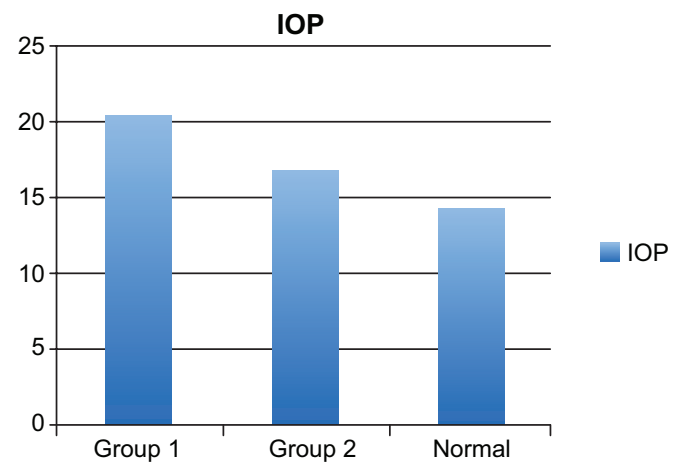

Figure 10 Mean values of IOP $(\mathrm{mmHg})$ by group.

Abbreviation: IOP, intraocular pressure.

7. Konstas AG, Stewart WC, Stroman GA, Sine CS. Clinical presentation and initial treatment patterns in patients with exfoliation glaucoma versus primary open-angle glaucoma. Ophthalmic Surg Lasers. 1997;28(2):111-117.

8. Izatt JA, Hee MR, Swanson EA, et al. Micrometer-scale resolution imaging of the anterior eye in vivo with optical coherence tomography. Arch Ophthalmol. 1994;112:1584-1589.

9. Hee MR, Izatt JA, Swanson EA, et al. Optical coherence tomography of the human retina. Arch Ophthalmol. 1995;113:325-332.

10. Pagliara MM, Lepore D, Balestrazzi E. The role of OCT in glaucoma management. Prog Brain Res. 2008;173:39-48.

11. Stratus OCT. Operation manual. Dublin, CA: Carl Zeiss Meditec Inc; 2002.

12. Weinreb RN, Dreher AW, Bille JF. Quantitative assessment of the optic nerve head with the laser tomographic scanner. Int Ophthalmol. 1989;13:25-29.

13. Garway-Heath D, Lemij H. Optic nerve head and retinal nerve fiber analysis. Eur Glaucoma Soc. 2005;Chapter 4:59-61.

14. Fingeret M. Using the Heidelberg retina tomograph II (HRT II): image acquisition and accessing the data. in: M. Fingeret, J.G. Flanagan, J.M. Liebmann (Eds.) The Essential HRT Primer. Heidelberg Engineering, Heidelberg, Germany. 2005;11-30.

15. Ferreri F, Aragona P, Ferreri G. Scanning laser polarimetry and confocal scanning laser ophthalmoscopy: technical notes on their use in glaucoma. Prog Brain Res. 2008;173:125-138.

16. Lester M, Mikelberg FS, Courtright P, et al. Correlation between the visual field indices and Heidelberg retina tomograph parameters. J Glaucoma. 1997;6:78-82.

17. Lan YW, Henson DB, Kwartz AJ. The correlation between optic nerve head topographic measurements, peripapillary nerve fibre layer thickness, and visual field indices in glaucoma. Br J Ophthalmol. 2003;87: 1135-1141.

18. Brigatti L, Caprioli J. Correlation of visual field with scanning confocal laser optic disc measurements in glaucoma. Arch Ophthalmol. 1995;113:1191-1194.

19. Weinreb RN, Shakiba S, Sample PA, et al. Association between quantitative nerve fiber layer measurement and visual field loss in glaucoma. Am J Ophthalmol. 1995;120:732-738.

20. Tole DM, Edwards MP, Davey KG, et al. The correlation of the visual field with scanning laser ophthalmoscope measurements in glaucoma. Eye. 1998;12:686-690.

21. Ritch R. Exfoliation syndrome-the most common identifiable cause of open-angle glaucoma. J Glaucoma. 1994;3(2):176-177.

22. Ritch R, Schlötzer-Schrehardt U, Konstas AG. Why is glaucoma associated with exfoliation syndrome? Prog Retin Eye Res. 2003;22(3): 253-275.

23. Greaney MJ, Hoffman DC, Garway-Heath DF, Nakla M, Coleman AL, Caprioli J. Comparison of optic nerve imaging methods to distinguish normal eyes from those with glaucoma. Invest Ophthalmol Vis Sci. 2002;43:140-145. 
24. Pierre-Kahn V, Tadayoni R, Haouchine B, Massin P, Gaudric A. Comparison of optical coherence tomography models OCT1 and Stratus OCT for macular retinal thickness measurement. $\mathrm{Br} J$ Ophthalmol. 2005;89(12):1581-1585.

25. Massin P, Vicaut E, Haouchine B, et al. Reproducibility of retinal thickness measurements in healthy and diabetic subjects using optical coherence tomography. Arch Ophthalmol. 2001;119: 1135-1142.

26. Burgansky-Eliash Z, Wollstein G, Bilonick RA, Ishikawa H, Kagemann L, Schuman JS. Glaucoma detection with the Heidelberg retina tomograph 3. Ophthalmology. 2007;114(3):466-471.
27. Ventura AC, Böhnke M, Mojon DS. Central corneal thickness measurements in patients with normal tension glaucoma, primary open angle glaucoma, pseudoexfoliation glaucoma, or ocular hypertension. $\mathrm{Br} \mathrm{J}$ Ophthalmol. 2001;85:792-795.

28. Klemetti A. Intraocular pressure in exfoliation syndrome. Acta Ophthalmol. 1988;184:54-58.

29. Huang D, Swanson EA, Lin CP, et al. Optical coherence tomography. Science. 1991;254:1178-1181.

30. Strouthidis N, Lester M, Garway-Heath D. Heidelberg retinal tomograph: the reference plane in optic nerve head and retinal nerve fiber analysis. Eur Glaucoma Soc. 2005; Chapter 4:63-65.
Clinical Ophthalmology

\section{Publish your work in this journal}

Clinical Ophthalmology is an international, peer-reviewed journal covering all subspecialties within ophthalmology. Key topics include: Optometry; Visual science; Pharmacology and drug therapy in eye diseases; Basic Sciences; Primary and Secondary eye care; Patien Safety and Quality of Care Improvements. This journal is indexed on

Submit your manuscript here: http://www.dovepress.com/clinical-ophthalmology-journal

\section{Dovepress}

PubMed Central and CAS, and is the official journal of The Society of Clinical Ophthalmology (SCO). The manuscript management system is completely online and includes a very quick and fair peer-review system, which is all easy to use. Visit http://www.dovepress.com/ testimonials.php to read real quotes from published authors. 